\title{
EROTISMO E METAMORFOSE NA POESIA DE ANTÓNIO FRANCO
}

\section{ALEXANDRE}

Paulo Ricardo Braz de Sousa ${ }^{1}$

RESUMO: Este trabalho objetiva uma leitura da obra Aracne, de António Franco Alexandre, fundamentada nas abordagens críticas que observam em seu texto um grande interesse pelas problemáticas envolvidas na relação entre mundo e linguagem. Para tanto, traz-se à baila a ideia de erotismo aliada à imagem da interlocução, de modo a articulá-la como valor ético.

PALAVRAS-CHAVE: António Franco Alexandre; erotismo; metamorfose; alteridade; ética.

\section{EROTISM AND METAMORPHOSIS IN THE POETRY BY ANTÓNIO FRANCO ALEXANDRE}

ABSTRACT: This paper aims to provide a reading for Aracne by António Franco Alexandre, based on critical approaches that analyze the problem of the connection between world and language. Therefore, the Idea of eroticism is understood as na image of dialogue, in order to articulate this with na ethical value.

KEYWORDS: António Franco Alexandre; erotcism; metamorphosis; otherness; ethics.

\footnotetext{
${ }^{1}$ Mestrando em Literatura Portuguesa pela Universidade Federal Fluminense - UFF.
} 
Se tivéssemos que demarcar alguns dos traços específicos que caracterizam a poética de António Franco Alexandre, certamente nos perderíamos em seus versos. Não bastasse uma produção que já abrange mais de quatro décadas, deparamo-nos com um autor muito afim a renovações em seu trabalho. Já Fernando Pinto do Amaral destacara, em texto de 1991, as constantes metamorfoses que a poesia alexandrina ensaia (AMARAL, 1991, p. 106), sem contar que, desde então, tais mudanças tornaram-se ainda mais acentuadas. Por outro lado, a tarefa apresenta uma série de complicações na medida em que mergulhamos, efetivamente, na obra de $\mathrm{AFA}^{2}$ : trata-se de uma linguagem esquiva, refratária, comprometida com um sentido outro próprio da poesia (CRUZ, 2008, p. 301), logo, a busca por localizar as balizas que sustentam esta edificação pode parecer, em outras palavras de Gastão Cruz, “uma viagem sem regresso” (CRUZ, 2008, p. 302), ou, como coloca o AFA d'A pequena face, cumprir certa prova de quem se tentou a "tecer um rumor em muros de água" (ALEXANDRE, 1996, p. 175).

Será Rosa Maria Martelo, todavia, quem, com extrema lucidez, situará a obra de AFA (precisamente o mais recente AFA) em meio às tensões da poesia portuguesa depois de 1961. Destacamos a palavra tensão justamente por a ensaísta apontar para caminhos de leitura desta obra que se encontram num espaço entre, referente à discussão em torno dos deslocamentos concernentes a uma tradição de modernidade "na qual a tentativa de articular arte e vida nunca estivera, na verdade, ausente" (MARTELO, 2007, p. 42). Ora, o que fica expresso no texto de Rosa Martelo é que esta poesia, fugindo de sínteses redutoras, buscaria coordenar as experiências textualistas, características dos poetas que vieram à tona na década de 60 (dentre os quais são assinalados Herberto Helder, Ruy Belo, assim como os jovens autores reunidos em Poesia 61), com uma abordagem de aspectos mais próximos do prosaísmo da cotidianidade, ou aquilo a que se chamou regresso ao sentido nos anos 70 (denominação, aliás, vista como indevida para certos críticos, tais como Gastão Cruz). Esclarecendo o quadro, será o próprio AFA quem afirmará que:

A poesia é (...), das artes da linguagem, o lugar do rigor, da precisão, da forma sensível organizada intelectualmente. Nem não se sabe que malabarismo verbal indiferente, nem mítica expansão de sensibilidades mal sofridas, mas afirmação do mundo e da linguagem, num gesto só, viver, escrever, apreender, criar, indissolúveis. (ALEXANDRE, 1984, p. 65-66).

Portanto, há intrínseca a esta concepção de labor poético a ideia de uma conjugação afirmativa entre as duas instâncias (que sejam mundo e linguagem) de forma que a constituição

${ }^{2} \mathrm{O}$ poeta passará a ser designado como AFA. 
incessante desse enlace necessita, fundamentalmente, da intervenção neste espaço, um corte sobre o corpo textual o qual proporcionará a construção de sentido. É certo, um texto precisa de seu leitor:

Leitor, ou crítico, terão antes de mais que entrar no espaço de pensamento vivo, no instrumento e lugar de conhecimento que o poema é, que 'discutir' a lição de real que o poema é, sob pena de se ficarem pela nulidade da impressão toscamente 'subjectiva'. (ALEXANDRE, 1984, p. 66).

Pois é exatamente neste espaço de confluência que se pretende desenvolver a análise de uma das obras do poeta. Aracne (2004), texto de maturidade de AFA, discute com propriedade o problema da interlocução, observando-a como esta ponte entre a arte e a vida. Habitar este "espaço de pensamento vivo", este "lugar de conhecimento", é a proposta essencialmente ética que nos é sugerida no instante de partilha de experiências que se faz a leitura, ou como é indicado numa espécie de definição de sua arte poética: "Se me prendo ao teu rumor ausente / não é que me consuma numa imagem / ou deseje real o imaginado; / é por outro real em ti presente.” (ALEXANDRE, 2002, p. 23). Nestes versos, a reivindicação de um encontro entre obra e leitor ganha uma potência assustadora, de forma que o exercício de alteridade como morte do autor por meio da escritura busca, consecutivamente, o outro; está à espreita de ouvidos que possam tomar estas palavras e rearranjá-las, fazer delas o instrumento de conhecimento para a transformação do mundo. O que se pode depreender deste movimento é certa complacência entre os elementos do par dialético perda e ganho, posto que a própria condição simultânea de ausência e presença, característica do signo linguístico, conforma o estado desejante em que se coloca o eu lírico. No entanto, como vemos, não interessa a esta poesia a perda pela perda, mas sim os efeitos provocados pela inscrição do sujeito em seu texto ao metamorfosear-se no corpo do outro.

Leiamos o fragmento retirado d'O prazer do texto de Roland Barthes:

Texto quer dizer Tecido; mas, enquanto até aqui esse tecido foi sempre tomado por um produto, por um véu todo acabado, por trás do qual se mantém, mais ou menos oculto, o sentido (a verdade), nós acentuamos agora, no tecido, a ideia gerativa de que o texto se faz, se trabalha através de um entrelaçamento perpétuo; perdido neste tecido - nessa textura - o sujeito se desfaz nele, qual uma aranha que se dissolvesse ela mesma nas secreções construtivas de sua teia. Se gostássemos dos neologismos, poderíamos definir a teoria do texto como uma hifologia (byphos é o tecido e a teia da aranha). (BARTHES, 2008, p. 74-75).

Barthes aponta para um delir-se do sujeito em seu texto de maneira que o sentido não mais se constitui como atributo dado em sua totalidade, mas gerado continuamente, 
logo, o sujeito em questão não mais pode ser compreendido como entidade estanque; pelo contrário, está fadado a constantes metamorfoses, só se pode dar a entender em movimento. A obra de AFA aqui estudada assim se inicia: "Gregor transformou-se em barata gigante. / Eu não: fiz-me aranhiço, / tão leve que uma leve brisa o faz / oscilar em seu fio de baba lisa.” (ALEXANDRE, 2004, p. 7). Deixando de lado, a princípio, o complexo de referências que já pode nos saltar aos olhos (Camões, Rimbaud, Kafka), somos tomados pelo curioso quadro de um eu lírico transmutado em aranha e, deste primeiro passo em seguida, são tecidas, em estrutura episódica, as suas pequenas aventuras lírico-amorosas. Interessa-nos, sobretudo, atentar à imagem do sujeito em trânsito, oscilante entre o eu e o outro. A prática radical de metalinguagem por meio da qual se dissipa o eu lírico concebe o movimento de alteridade que, consecutivamente, impossibilita o leitor de demarcar com precisão o terreno por onde caminha, instituindo, assim, os efeitos de indecidibilidade que Rosa Martelo diagnostica em seus versos (MARTELO, 2009, p. 265). Ora, a linguagem de AFA não só se apresenta como falta ao seu receptor, fazendo-o investir-se num exercício de leitura vertical (como o quer a estrutura do poema), como expõe estas lacunas de sentido, o espaço oco do texto (MARTELO, 2009, p. 280281), sendo frequente o jogo de espelhamento entre obra e leitor. Assim como afirma o eu lírico de Aracne que "É verdade que a morte se embaraça / na trança irregular da minha tela;" (ALEXANDRE, 2004, p. 27), não sabemos ao certo se também nós, leitores, não morremos aos poucos ao nos enredar em sua teia, para que então se gerem outros sentidos: novos sentidos.

Nesta altura, cumpre ressaltar o papel fundamental desempenhado pelo erotismo na poesia alexandrina. É por meio de tal perspectiva de investigação que, enfim, se pretende pôr em causa esta que, possivelmente, seria uma das temáticas mais recorrentes em seus textos. Na esteira da leitura de Fernando Pinto do Amaral, que enxerga no eros desta obra a irreversibilidade do apagamento dos sujeitos amantes a partir do encontro de seus corpos, busca-se determinar como, a partir da escritura do outro no tecido poético, se conformam as figurações eróticas em Aracne. Desta forma, tal fenômeno interessa, sobretudo, na medida em que se observam as problemáticas envolvidas no encontro entre obra e leitor, desvelando a prática de construção de sentido como movimento líricoamoroso. Como se pretende discutir, o erotismo no texto de AFA põe em questão as severas implicações éticas da poesia portuguesa contemporânea ao se situar naquele espaço de tensão em que se procuram articular vida e arte. A encenação dos movimentos de metamorfose que levam à transformação do amador na cousa amada reivindicada por esta 
poesia é o que se procura estudar, levando-se em conta esta breve proposição: o encontro (erótico) entre obra e leitor é o que possibilitaria fazer vibrar os fios que amarram mundo e linguagem e que suscitaria a afirmação de ambos a partir deste mesmo enfrentamento.

Um primeiro problema que se nos apresenta diz respeito à constituição valorativa da experiência erótica. Como afirma Bataille: "o erotismo é considerado uma experiência ligada à experiência da vida, não como objeto de uma ciência, mas da paixão, mais profundamente, de uma contemplação poética.” (BATAILLE, 2004, p. 14). Ora, entregarse às faculdades de discernimento concernente ao pathos amoroso compreende, naturalmente, uma perspectivação em desequilíbrio. A desordem própria do erotismo é acompanhada de sua (in)sujeição analítica. Observemos que, quando Bataille declara que o erotismo é "aprovação da vida até na morte" (BATAILLE, 2004, p. 19), a noção de ambivalência nos parece iluminar esta assertiva mais do que propriamente uma ideia de superação (a qual é muito afim a tal movimento). Natural é a observação dos opostos complementares aliados à lógica amorosa na medida em que são pensados como valor ético, posto que, num momento limite, são notados em sua íntima contradição. Isto se explica, também, pela confluência entre contenção e excesso, o que caracteriza o homem no erotismo, distanciando-o da animalidade. Pensando em Aracne, detemo-nos a princípio numa questão que, por mais que pareça irrelevante, toma as rédeas do texto: o eu lírico da referida obra transforma-se num aranhiço, revela-se, de antemão, um ser em trânsito. Não penso, aqui, numa analogia com a reprodução dos animálculos de Bataille (2004, p. 25) - a qual se associa a um movimento de continuidade visto como rudimentar pelo ensaísta ${ }^{3}-$, mas na concepção de metamorfose e na indiferenciação proveniente de tal fenômeno. Como o próprio Bataille nos explica, somos seres descontínuos. Tal descontinuidade é percebida na solidão experimentada pelo homem na singularidade de sua existência, a separação dos corpos que nos relega a uma distância supostamente intransponível. Todavia, este mesmo abismo aberto, que marca a diferença entre os seres, é a porta para o desejo.

O erotismo é, essencialmente, encontro com o outro. Da prisão vivenciada na descontinuidade, lança-se em direção a experiência de morte que o movimento erótico ensaia (uma pequena morte) (BATAILLE, 2004, p. 156). Deste modo, este não é um salto para o vazio, trata-se de uma morte transitiva, de uma experiência da continuidade do ser no outro. Tal exercício de deslocamento proporciona não somente uma fusão dos corpos -

\footnotetext{
${ }^{3}$ Vale lembrar, aliás, que, na obra alexandrina, o eu lírico transmutado em aranha deseja um encontro com seu amante humano; imagem que, mais adiante, procura se conceber como a con-fusão dos corpos enamorados, no diálogo obra/leitor.
} 
a transformação do amador na cousa amada, no dizer de Camões -, como também uma mudança do corpo em si após o vislumbre do espanto provocado pela continuidade.

Lemos em Aracne: “O corpo, é certo, 'todo de olhos feito', / é o mais belo e mais sensível fruto / da natureza, e a todos causa espanto;" (ALEXANDRE, 2004, p. 12). A beleza apontada nestes versos importa na medida em que a concebemos nos limites de um transbordamento. Como objeto de desejo erótico, impõe-se a interdição unicamente para se resultar, do encontro entre os amantes, a transgressão. E desta transgressão supõem-se as mais vertiginosas manifestações de angústia e horror propiciadas pela projeção na continuidade, na medida em que de forma mais brutal transpõem-se os limites precisos da interdição. A expressão do belo exaltado pelo eu lírico é uma ameaça, por si só um dilaceramento, posto que compreende em sua constituição as formas do ilimitado. Nas palavras de Bataille: "O limite só é dado para ser excedido. O medo (o horror) não indica a verdadeira decisão. Ao contrário, ele incita, por via indireta, a transposição dos limites." (BATAILLE, 2004, p. 226). A presença da beleza é uma constante na apreciação do ser amado pelo aranhiço, demarcando, assim, a fronteira a ser transposta pelo desejo, a qual é devassada, "numa raiva de apetite", expondo-se radicalmente a confluência entre humanidade e bestialidade. A figura do híbrido, imageticamente representada pelo vampiro em dado momento, corrobora para a ilustração desta queda. Aqui, a certeza de fazer o Mal, ao render-se ao excesso no encontro com o corpo do amado, é algo que se pode inferir na observação de elementos que oferecem a dimensão do sagrado ${ }^{4}$. A posição ascética em que se coloca o aranhiço também nos ajuda a compreender certo sentido de elevação entretanto, uma elevação pela carne, consumada na experiência erótica:

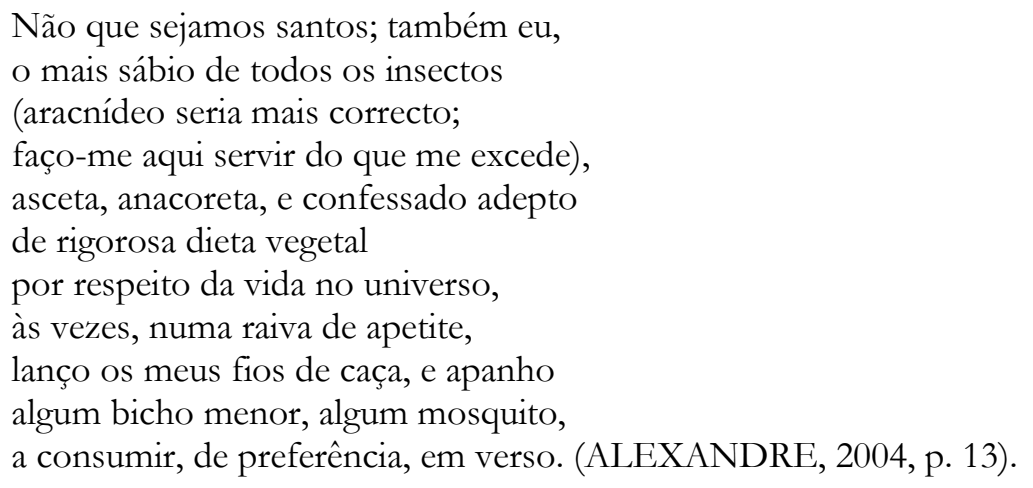

Fica evidente, neste trecho, a configuração do deslimite próprio do erotismo, então muito próxima da violência que caracteriza este movimento. Este eu lírico, que se faz servir do que o excede, apresenta constantemente indícios de uma ideia de projeto, muito cara a

\footnotetext{
${ }^{4}$ Neste caso, a ideia de sagrado em nada tem que ver com a concepção do cristianismo, em que se dá a eliminação da violência na experiência religiosa.
} 
esta poesia. Um exercício de alteridade se conforma, então, às especificidades de uma possessão erótico-lírica no poema de AFA. A relação desta poesia com a questão da continuidade, discutida anteriormente, se faz, assim, por meio do relacionamento entre obra e leitor, o que nos sugere outras problemáticas como veremos mais adiante.

A obra Ascese, de Nikos Kazantzákis, vem ao encontro de tais questões levantadas, cumprindo associar o exercício ascético encerrado no texto de AFA à construção de sua poética. A narrativa de Kazantzákis interessa, e em muito, para o desenvolvimento de uma proposta de leitura que articule as inquietações recorrentes na lírica de AFA referentes a uma problematização da liberdade com os efeitos de sentido gerados pela condução dos ensinamentos propostos pelo narrador de Ascese. Uma incessante luta para o autoconhecimento, tendo em vista a inexorável condição de ignorância do homem perante as questões fundamentais, é um ponto de partida.

Qual é a essência de nosso Deus? A luta pela liberdade. Dentro das trevas indestrutíveis, uma linha de fogo ascende e assinala o curso do Invisível. Qual é o nosso dever? Ascender com ele por essa linha ensanguentada. (KAZANTZÁKIS, 1997, p. 122).

Ascese: prática de rigorosa disciplina que visa o aperfeiçoamento espiritual ou a excelência no domínio de dado conhecimento. Por meio desta brevíssima asserção - que aqui se presta a serviço da praticidade -, pode-se engendrar as concepções, também pertinentes, de elevação, do desenvolvimento de determinado saber que possibilite " $O$ acesso a um estudo superior". Como já é possível observar, a ascese, que interessa para este trabalho, está intrinsecamente ligada a um desejo de liberdade; processo que, afinal, deve ser configurado como uma incessante batalha entre duas forças antagônicas que movimentam o Universo (uma descendente, outra ascendente), ou, mais precisamente, a busca por este instante de suspensão na confluência entre ambas as potências. A primeira delas compreende a destruição, a inércia, a ruína. Já a última diz respeito a um impulso de constante ação, sem, no entanto, prometer mais que este Grito pela marcha adiante, a passagem por entre gerações do gosto pela aventura humana a qual almeja ultrapassar sua própria condição para abraçar a eternidade.

No entanto, no âmbito da obra de AFA, tal concepção de liberdade pode nos parecer absurda, já que, de acordo com a própria lógica do erotismo (como o estamos estudando), é preciso determinar os limites de uma interdição. A atividade erótica necessita da constituição destas fronteiras para que, assim, seja possível engendrar-se a transgressão. Sem interdição, não há o que se transgredir; sem a violência da transgressão, não há o gozo 
erótico. O encontro com o sagrado que procuramos entender em Aracne partiria da premissa de que o material poético, essencialmente, pressupõe uma fratura sobre a ordem, assimilando-se, deste modo, ao confrontamento da continuidade a qual é revelada pelo encontro sexual dos corpos. Este é o movimento de ação e retração, muito bem observado por Rosa Martelo, o qual é permitido desenvolver tendo em vista o estabelecimento do limite a ser consecutivamente transgredido. Sendo a vida um excesso, porque empreende a todo instante (e para a sua continuidade) o extravasamento do encontro erótico, observamos, consequentemente, o tempo como instância relativa à constituição ética do erotismo.

Ora, é porque o homem possui consciência que ele se reconhece um ser para a morte. O transcorrer do tempo nos revela a face da morte e a brevidade da vida: "É breve a vida; mal sabemos / fiar um fio, e conceber a seda, / já se gastou a areia na ampulheta;" (ALEXANDRE, 2004, p. 36). A atividade poética, assimilada ao gesto amoroso, empreende este corte sobre o véu do tempo, a vontade de superá-lo. Entretanto, ao exigir a sua superação, o reconstitui, promovendo incessantemente isto que Bataille denomina o curso natural da vida. A ideia de liberdade, que aqui se supõe, não pode ser mais que provisória; em Aracne, evidencia-se esta busca por uma espécie de tempo fora do tempo, a superação da morte no encontro erótico com o outro. Mas o desencanto perante a passagem do tempo nos revela a outra face da existência: o seu termo na morte intransitiva, a queda no vazio. Explica-nos o eu lírico de Aracne que não há como escapar a tal perspectiva, "porque o tempo / é, como eu, um mero fabricante / de véus e teias que os humanos rasgam / sem sentir como nelas estão presos." (ALEXANDRE, 2004, p. 37). Contra o seu próprio desaparecimento, o que o aranhiço almeja está próximo de um movimento ascético pela carne, a presentificação do sagrado conduzida pela violência do choque entre os corpos amantes que o leva à experiência da continuidade.

O sentido de elevação assinalado em Aracne assume uma perspectiva deveras particular, em meio à tensão provocada entre a pulsão sexual e a linguagem, na medida em que se coaduna com um projeto de constituição lírica que se move num espaço de confluência entre corpo e material poético. Entretanto, Aracne é, acima de tudo, um texto afirmativo, entende as contradições de seu tempo como consequentes manifestações da própria natureza humana. Deste modo, eis o diálogo (im)possível na obra de AFA, o horizonte que encerra a luta pela liberdade (mesmo que sejamos sempre a presa de sua teia), impulso de criação constante, o ânimo que move, neste caso especificamente, a produção poética por meio da interlocução. 
Como observamos anteriormente, em Aracne são postas em conflito duas concepções de morte, entre o agônico movimento de continuidade característico do erotismo (de afirmação da própria vida) e a morte física intransitiva. O que se deve ressaltar deste quadro é o fato de o aranhiço enamorado estar constantemente à espreita dos dois abismos abertos à sua frente. Separando um do outro, há a interlocução. É ela que, supostamente, dribla o esquecimento e lança à eternidade a palavra proferida: o Grito visto em Kazantzákis.

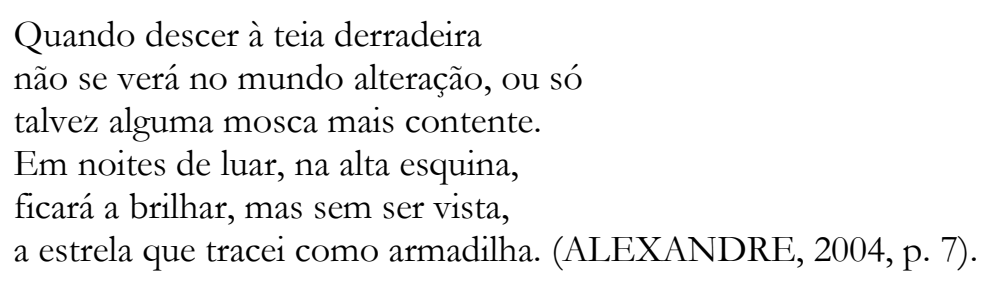

Os versos de AFA, numa espécie de sinistra (e não menos irônica) antecipação de fala dirigida aos seus contemporâneos, já supõem o castigo terrível ${ }^{5}$ após uma morte que não implica "no mundo alteração". O jogo, aqui, é em torno do duplo alteração/alteridade. Por trás de um dissimulado tom blasé frente à curva cadente de sua teia, o aranhiço é obrigado a se defrontar com a face mais amarga da existência: a solidão do ser descontínuo em direção à morte. Por outro lado, com um tanto de mistério, adivinha a sua estrela a brilhar, como uma armadilha. Sob a lógica aqui pretendida, a ausência de interlocução é a abertura ao vazio, a queda derradeira que não propicia mudança alguma no real, enquanto que o projeto de alteridade desejado pelo eu lírico é a possibilidade de engendrar o encontro erótico, a transformação do sujeito e do mundo. A oscilação em que se encontra o aranhiço é, afinal, estado de suspensão entre o eu e o outro, entre a obra e o leitor, entre a arte e a vida. Aqui, voltamos ao ponto de onde partimos.

Leiamos este fragmento de Aracne:

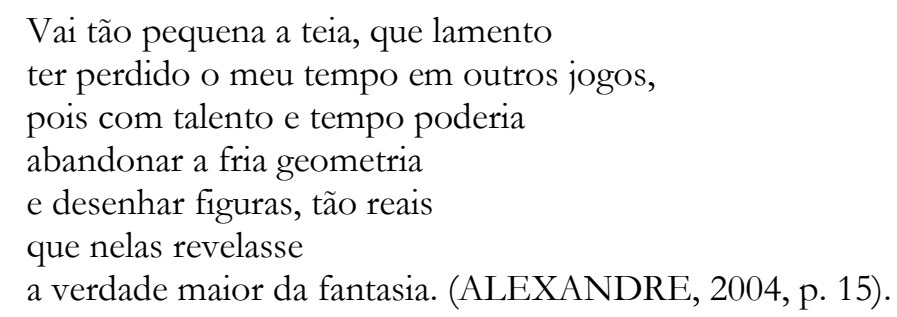

Está evidente: o tempo é fator de fundamental importância para o entendimento desta ética que, então, se pretende problematizar. Neste âmbito, os versos de Aracne em destaque corroboram esta premissa. O lamento do eu lírico dá-se em virtude da perda de

\footnotetext{
${ }^{5}$ (SENA, 1977, p. 99)
} 
tempo; da mesma maneira, a constituição de um projeto poético em que se efetiva a projeção do eu a partir do atravessamento proporcionado pela palavra é trabalho encerrado no tempo. Contudo, também não deixa de ser busca da eternidade no outro.

Sobre este movimento paira a incerteza. O destino que cumprirão as palavras ditas é um caminho indecifrável, isto que oscila entre o rumor da voz e um ouvido impertinente. Enfrentar os desafios desta empreitada é o que faz a poesia de AFA, assim como a de tantos outros, de diferentes modos. A obra de Gastão Cruz, A moeda do tempo, em muito pode nos ajudar a compreender este fenômeno. Podemos ler, no poema O próprio mundo, por exemplo, a imagem de um corpo poético milenar em consonância com uma efetiva prática de transformação da realidade, por meio do encontro com o outro:

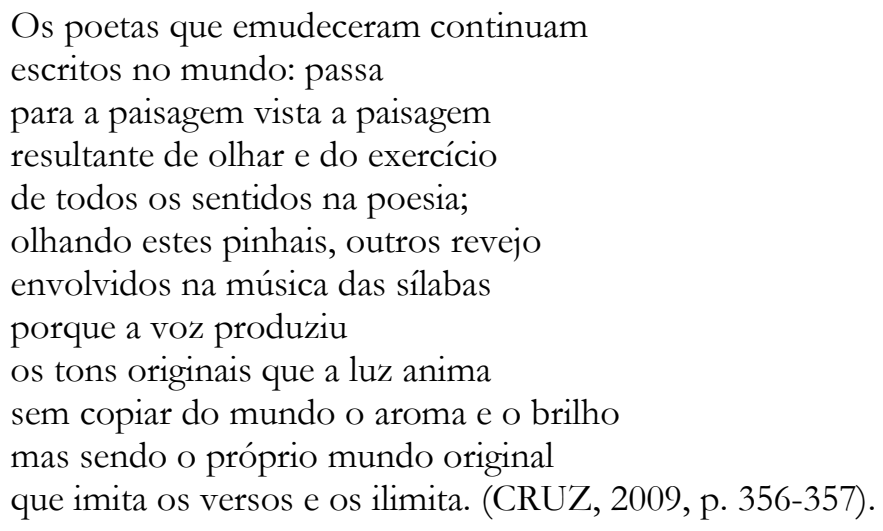

O diálogo que este poema nos suscita é entre poetas. Mais do que a angústia da influência, nos sobressalta a configuração de um movimento afluente ou, mais precisamente, confluente. O poema, aqui, é um veio de água lutando entre os meandros de pedra para se juntar aos demais, é inscrição do mundo, "o próprio mundo" afirmado como palavra viva, ilimitada na voz de outros tantos poetas. Retoma-se a ideia de continuidade como acordo selado entre obra e leitor. Neste âmbito, a palavra poética não somente flui para dentro do outro a lhe alterar os modos de ser, mas flui com o outro se derramando amorosamente num mesmo leito. Empenha-se numa luta entre iguais ensaiando novos movimentos de transformação: “(...) depois, teu igual, talvez te vença / ou me deixe vencer, e te pertença / com a vaidade que me vem de ter / o sábio coração de um aranhiço." (ALEXANDRE, 2004, p. 47). Aracne encerra-se com estes versos, os quais em muito nos fazem lembrar certa passagem de famoso soneto camoniano o qual diz que o "[Amor] É um cuidar que ganha em se perder". Assim, entre ganhos e perdas, a obra de AFA nos mostra, afinal, que o poema, sendo lugar de pensamento vivo, é, consecutivamente, espaço de encontro e reconciliação. Corpo aberto para a nova metamorfose. 


\section{Referências:}

ALEXANDRE, António Franco. Aracne. Lisboa: Assírio \& Alvim, 2004. Duende. Lisboa: Assírio \& Alvim, 2002.

. “Gastão Cruz: Poesia 1961-1981”. In. Revista Colóquio/Letras. Notas e Comentários, no 81, p. 65-68, Set. 1984. Poemas. Lisboa: Assírio \& Alvim, 1996.

AMARAL, Fernando Pinto do. A fala imperceptível de António Franco Alexandre. In. O mosaico fluido: Modernidade e pós-modernidade na poesia portuguesa mais recente. Lisboa: Assírio \& Alvim, 1991.

BARTHES, Roland. O prazer do texto. Trad. J. Guinsburg. São Paulo: Perspectiva, 2008.

BATAILLE, Georges. O erotismo. Trad. Cláudia Fares. São Paulo: Arx, 2004.

CAMÕES, Luis de. Rimas. Texto estabelecido e prefaciado por Álvaro Júlio da Costa Pimpão. Coimbra: Atlântida Editora, 1973.

CRUZ, Gastão. Oásis de António Franco Alexandre ou "o laço cego do poema”. In. A vida da poesia. Lisboa: Assírio \& Alvim, 2008. Os poemas. Lisboa: Assírio \& Alvim, 2009.

KAZANTZÁKIS, Nikos. Ascese: Os salvadores de Deus. Introdução e tradução de José Paulo Paes. São Paulo: Editora Ática, 1997.

MARTELO, Rosa Maria. “O ‘especialista em sublimação’ e os usos da linguagem (acerca da poesia de António Franco Alexandre)". In. Cadernos de Literatura Comparada - Artes da Perversão. Porto: Instituto de Literatura Comparada Margarida Losa da faculdade de Letras da Universidade do Porto. n 20, p. 261-283, Junho de 2009.

Vidro do mesmo vidro: Tensões e deslocamentos na poesia portuguesa depois de 1961. Porto:

Campo das Letras, 2007.

SENA, Jorge de. Poesia. Lisboa: Moraes, 1977.

\section{Artigo recebido em: 30 de Março de 2012.}

Artigo aprovado em: 15 de Outubro de 2012. 